
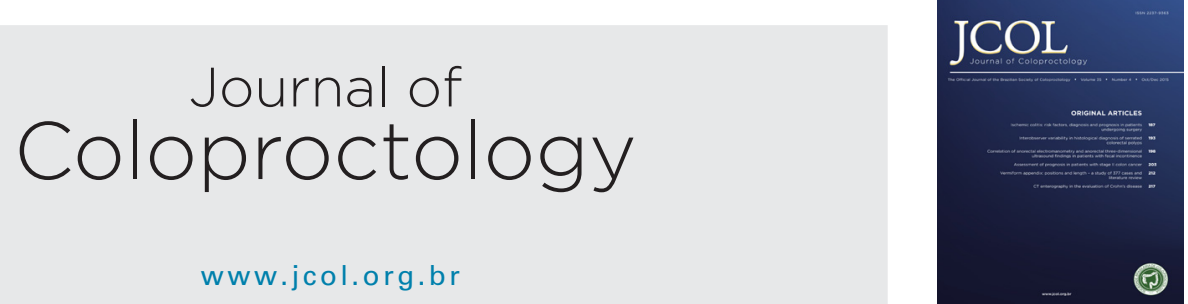

Original Article

\title{
Evaluation of outcomes in fissurectomy and V-Y advancement flap for the treatment of chronic anal
} fissure

\author{
Fakhrosadat Anaraki ${ }^{a}$, Tahereh Foroughifar ${ }^{b}$, Seyed Hossein Laleh ${ }^{a}$, Omid Etemad ${ }^{c, *}$ \\ a Shahid Beheshti University of Medical Sciences, Taleghani Hospital Research Development Unit, Colorectal Division of Surgical Ward, \\ Tehran, Iran \\ b Tehran University of Medical Sciences, Baharloo Hospital, Department of Pelvic Floor Surgery, Tehran, Iran \\ c Tehran University of Medical Sciences, Imam Khomeini Hospital Complex, Plastic \& Reconstructive Surgery Ward, Tehran, Iran
}

\section{A R T I C L E I N F O}

Article history:

Received 15 November 2017

Accepted 3 February 2018

Available online 18 February 2018

Keywords:

Fissurectomy

V-Y advancement flap

Chronic anal fissure

\section{A B S T R A C T}

Chronic anal fissure is difficult to treat. Surgery is usually recommended in the case of drug therapeutic failure. Fecal incontinence in patients with weaker sphincters (multipara older patients with a history of pelvic surgery etc.) is a major reason for rejecting surgery. Such these patients should be underwent fissurectomy and V-Y advancement flap in which sphincterotomy is not required. In this prospective study, we determined the outcomes and complications of fissurectomy and V-Y advancement flap in both groups of patients with low and high anal sphincter tones.

(c) 2018 Sociedade Brasileira de Coloproctologia. Published by Elsevier Editora Ltda. This is an open access article under the CC BY-NC-ND license (http://creativecommons.org/ licenses/by-nc-nd/4.0/).

Avaliação de desfechos na fissurectomia e retalho de avanço em V-Y para o tratamento de fissura anal crônica

R E S U M O

A fissura anal crônica tem tratamento difícil. A cirurgia geralmente é recomendada em caso de falha do tratamento medicamentoso. A incontinência fecal em pacientes com esfíncteres mais fracos (pacientes multíparas mais velhas com história de cirurgia pélvica etc.) é uma razão importante para a rejeição da cirurgia. Esses pacientes devem ser submetidos a fissurectomia e retalho de avanço em V-Y no qual a esfincterotomia não é necessária. Neste

\footnotetext{
* Corresponding author.

E-mail: omid.etemad@yahoo.com (O. Etemad).

https://doi.org/10.1016/j.jcol.2018.02.001

2237-9363/@ 2018 Sociedade Brasileira de Coloproctologia. Published by Elsevier Editora Ltda. This is an open access article under the CC BY-NC-ND license (http://creativecommons.org/licenses/by-nc-nd/4.0/).
} 
estudo prospectivo, determinamos os desfechos e complicações da fissurectomia e o retalho de avanço em V-Y em ambos os grupos de pacientes com tônus baixo e alto do esfíncter anal.

(C) 2018 Sociedade Brasileira de Coloproctologia. Publicado por Elsevier Editora Ltda. Este é um artigo Open Access sob uma licença CC BY-NC-ND (http://creativecommons.org/ licenses/by-nc-nd/4.0/).

\section{Introduction}

Anal fissure is painful situations and appeared below the dentate line which may be caused by a wound or a tear in anal canal anoderm. Stretching of the anal mucosa beyond its normal capacity is suggested as an etiology. ${ }^{1}$ Some other factors may lead to fissure is childbirth trauma in women, defecation caused by constipation, chronic diarrhea, anal sex, history of anal area surgeries, chronic diseases and ulcerative colitis. ${ }^{2,3}$

While acute fissure typically heal after 4-6 weeks, chronic fissured persist beyond 12 weeks. ${ }^{3}$ A fissure usually presents with anal pain, spasm and/or bleeding with defecation. Its prevalence in adults is 1 in 350 and is more common in women.

There are different methods to treat anal fissure include medication, laser therapy and surgery. Non-surgical treatment methods are initially recommended for acute and chronic fissures. ${ }^{4-6}$

Some studies showed that V-Y advancement flap could be a primary therapy for patients with chronic fissures. ${ }^{7}$ In a study, 54 patients underwent a V-Y advancement flap over 7 year period. $78 \%$ of them had failed a previous therapy. On followup at 6 months, all but one patient had healed wound.

The treatment of chronic anal fissure is still challenging. ${ }^{1}$ For chronic fissures, medication has been useful in $60 \%$ of patients; while in others, a resistance to medication has been observed. These patients are candidate to be injected by botulinum toxin to anal sphincter, fissurectomy and V-Y flap in which sphincterotomy is not required.

In this study, we evaluated the complications and outcomes of this surgical method using fissurectomy and V-Y flap for patients with low and high anal sphincter tone.

\section{Material and methods}

We studied 30 consecutive patients with chronic anal fissure who underwent fissurectomy combined with V-Y flap, among patients who were referred to Taleghani hospital of Tehran during 2015-2017.

Persistent signs and symptoms of chronic anal fissures that last more than 12 weeks and resistant to medication were our inclusion criteria. Resistant to medication was found when fissures did not heal within 3 months of applying $2 \%$ diltiazem ointment 3 times a day in patients with a high sphincter tone and triple therapy (hydrocortisone, zinc oxide, lidocaine) in patients with low anal sphincter tone.

Exclusion criteria included atypical fissure such as multiple, irregular and off the midline fissures, syphilis, tuberculosis and malignant disease.

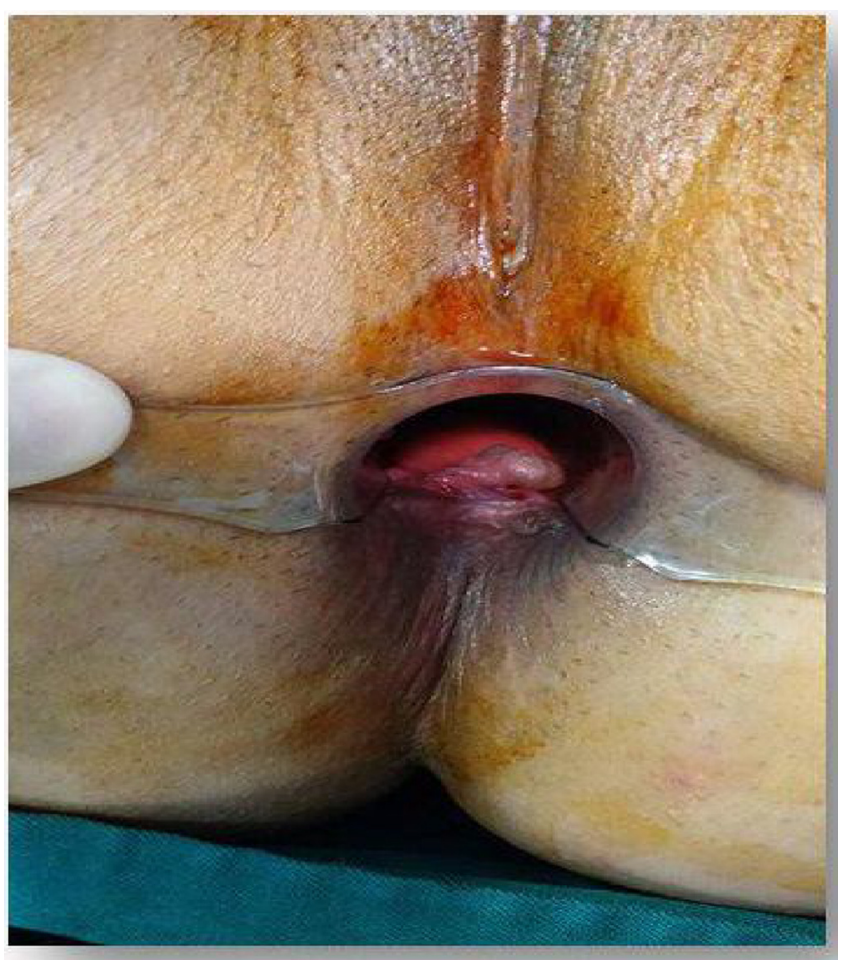

Fig. 1 - Chronic anal fissure.

Fissurectomy was performed under general/regional anesthesia after informed consent in position of lithotomy. Fig. 1 shows the chronic anal fissure.

During the fissurectomy, fissure edges and sentinel skin tag were excised. In some cases, we need to resect hemorrhoid or hypertrophic anal papilla. In Fig. 2, fissurectomy is seen.

As it can be found in Fig. 3, V-Y advancement flap was created by a V-shape rent in $4 \mathrm{~cm}$ away from anal verge diverting away from the midline. Then the V-shaped skin was moved to the inner of anal canal in order to cover the defect.

Demographic data (age, sex, weight, etc.), medical history, signs and symptoms (pain, location of pain, fecal incontinence, wound infection, wound dehiscence) after 3, 6 and 12 months were collected. Fig. 4 shows the cosmetic results of fissurectomy after 4 month.

Incontinence was documented according to the Wextner Score. ${ }^{8}$ All data were analyzed and a $p<0.05$ was considered significant. 


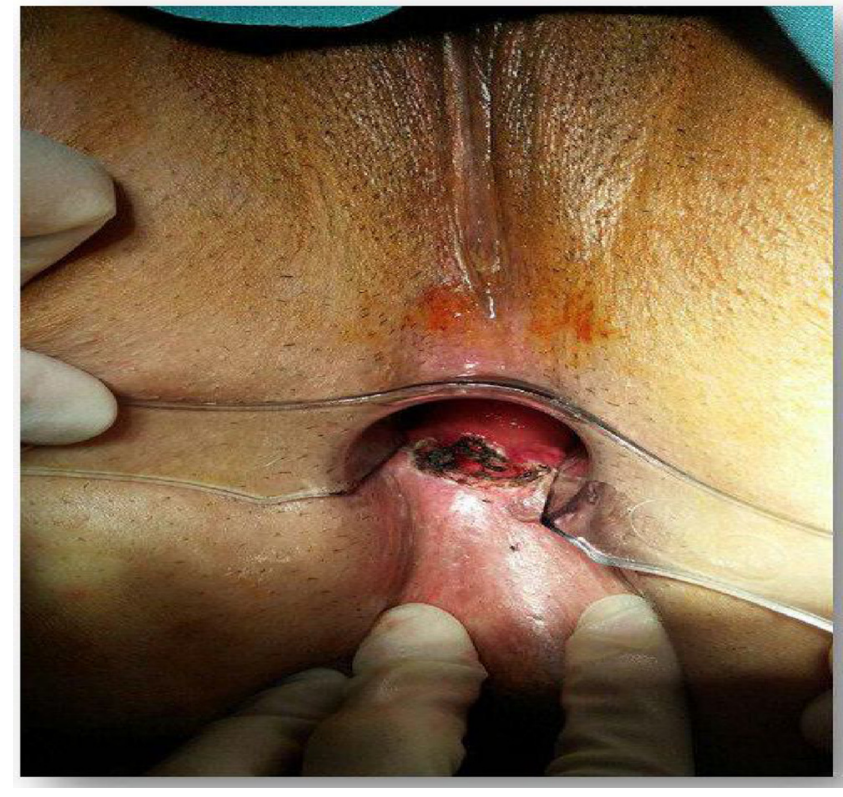

Fig. 2 - Fissurectomy.

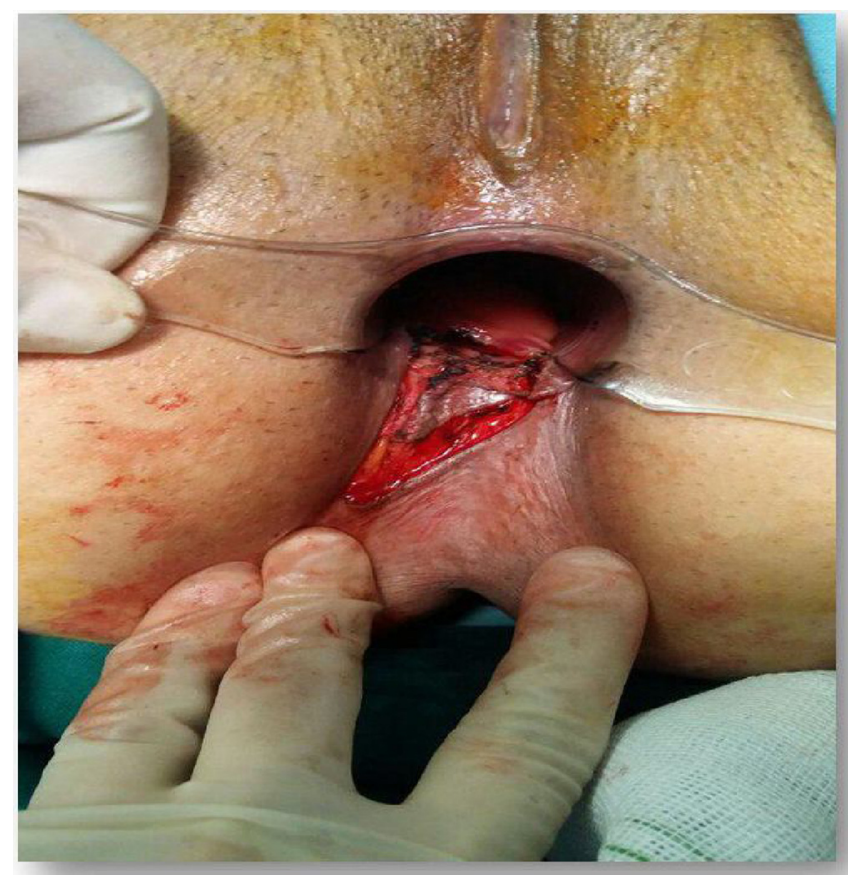

Fig. 3 - Fissurectomy and V-Y advancement flap.

\section{Results}

Thirty patients (25 women) with a mean age of 40.63 yrs (ranging from 18 to $57 \mathrm{yrs}$ ) were enrolled into our study. Both groups of patients with low and high anal sphincter tone entered the study. All of them underwent fissurectomy combined with V-Y flap. Mean follow-up was 16.6 months (ranging from 3 to 33 months).

Twenty eight patients experienced failure in medication therapy before our study (93.3\%). Four of these 28 patients had

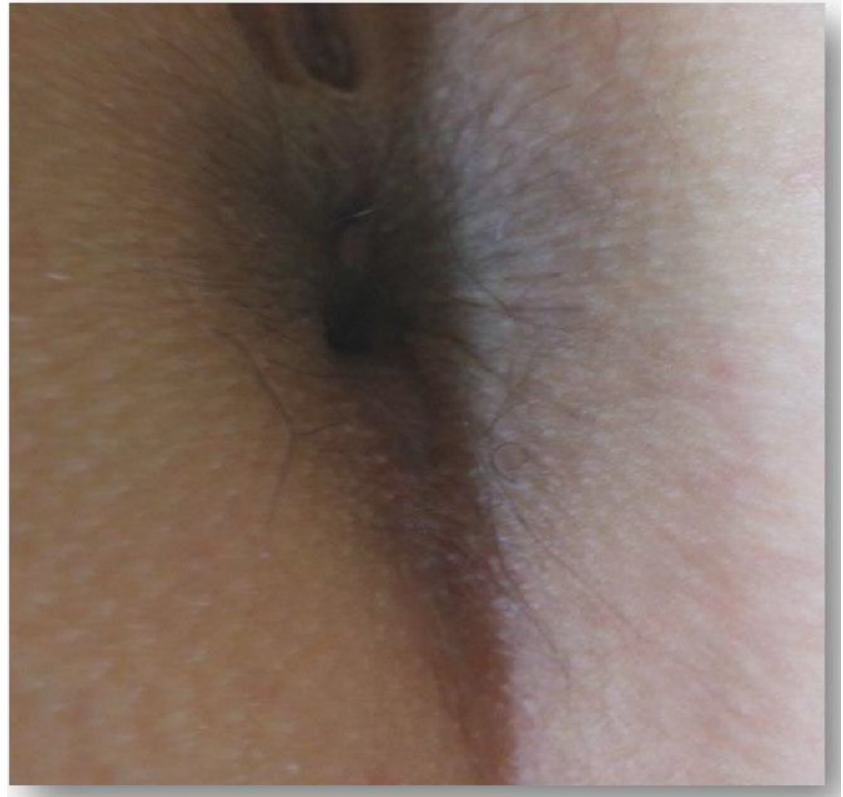

Fig. 4 - Four months after creating V-Y advancement flap.

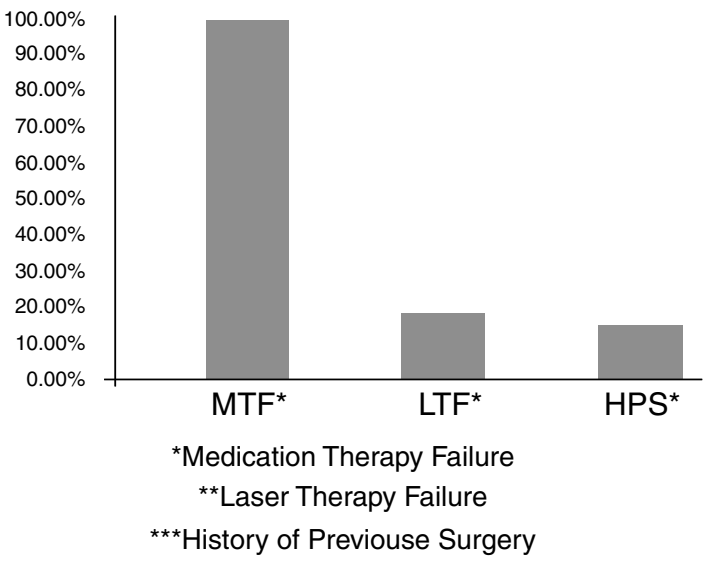

Fig. 5 - History of patients.

a history of laser therapy (13.3\%) and three of them had a history of previous surgery (10\%). These results are collected in Fig. 5.

Before surgery, 10 patients had a high sphincter tone (33.3\%), 17 patients had a normal tone $(56.7 \%)$ and 3 patients were referred with a low sphincter tone $(10 \%)$. As you can find in Fig. 6, after the surgery, high sphincter tone was seen in 3 patients (10\%); low sphincter tone remained the same for 3 patients $(10 \%)$, and 24 patients had a normal sphincter tone (80\%).

Three months after the surgery, all patients were reevaluated, examined and interviewed in colorectal clinic. Four patients complained of local pain (13.3\%), but the pain was not present in other 26 patients (86.7). One patient presented with wound dehiscence and wound infection signs were seen in one patient. Fecal incontinence was not reported.

We continued our follow-up after 6 and 12 months. In 6th month, one patient had local pain (3.3\%) which was reduced 


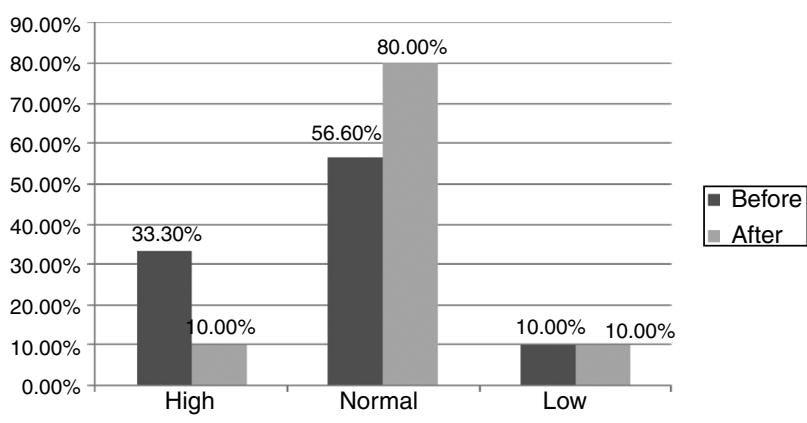

Fig. 6 - Comparison of patients sphincter tone, before and after the surgery.

\begin{tabular}{llll}
\multicolumn{4}{l}{ Table 1 - Short/long term follow-up outcomes. } \\
\hline Symptoms & 3rd month & 6 th month & 12th month \\
\hline Pain & $13.3 \%$ & $3.3 \%$ & 0 \\
Wound dehiscence & $3.3 \%$ & $3.3 \%$ & $3.3 \%$ \\
Wound infection & $3.3 \%$ & 0 & 0 \\
Fecal incontinency & 0 & 0 & 0 \\
\hline
\end{tabular}

up to $10 \%$ in compare with 3 rd month. One patient presented wound dehiscence. In 12th month of our follow-up, no local pain and no wound dehiscence was presented and none of them reported fecal incontinence. Follow-up data are collected in Table 1.

\section{Discussion}

This study has shown an excellent outcome in long term follow-up on patients with chronic fissure who were undergone the fissurectomy and V-Y flap. Both groups of low and high anal sphincter tone entered the study. Our results show successful treatment of chronic fissure 12 months after the surgery.

Applying V-Y advancement flap on 51 patients with chronic anal fissure showed a $98 \%$ healing rate with a flap dehiscence rate of $5.9 \%$ and $0 \%$ incontinence rate and a recurrence rate of $5.9 \%$ of new fissure at new locations. ${ }^{9}$

Fecal incontinence, hemorrhage, urinary retention and keyhole defects are frequently side effects of fissurectomy. ${ }^{10}$ In recent years, there has been occurred a shift toward medical therapy to overcome surgical side effects. According to British Coloproctology Protocol, if the medication therapy does not heal the wound after 6-8 weeks, botulinum injection is recommended. ${ }^{11}$ If the wound does not heal after 2-3 months from injection, then lateral internal sphincterotomy will be performed for patient. These steps may take about 8-9 months.

An excellent rate of healing of chronic anal fissures treated with a V-Y advancement flap were shown in a study of William and etc. ${ }^{12}$ These results showed that regardless of sphincter pressure, previous treatment and symptom chronicity, this technique was successfully applied on 55 patients and all but one of them had a healed wound and was asymptomatic.

From 2002 to 2008, a prospective study was done by Patti et al. on 106 patients in whom medication therapy has been failed. ${ }^{13} 58$ patients with CAF underwent fissurectomy and anal advancement flap. In 22 cases with hypertonia of internal anal sphincter, intra-sphincter injection of $30 \mathrm{UI}$ of botulinum was performed. All patients were followed-up up to 24 months. Since the first defecation, the intensity and duration of pain were significantly reduced. Two and 5 patients experienced urinary retention and infection, respectively. No anal stenosis, keyhole deformity or necrosis was reported. After 24 months, anal incontinence was similar to those detected preoperatively. Only four recurrences were reported at 18 and 20 months. This study concluded that fissurectomy with advancement flap is a valid sphincter-conserving procedure to treat anterior/posterior CAF in the case of medication therapy failure, regardless of hypertonia of the internal sphincter.

\section{Conclusion}

Considering this fact that anal fissures are disturbing and painful problem and medical therapy and botulinum injection are effective in $60 \%$ of cases, and ACPGBI protocol takes from 8 to 9 months to reach to the surgery step, we suggested fissurectomy combined with V-Y advancement flap. This method is also recommended because:

1. This method terminates patient's physical discomfort.

2. Employing this method, will not require frequent doctor-patient visits.

3. In comparison with medication therapy and botulinum injection, this method is low cost.

In other hands, because of high chance of incontinence, lateral internal sphincterotomy cannot be performed for the patients with low sphincter tone.

In this study, fissurectomy combined with V-Y advancement flap was performed for 30 patients. Fecal incontinence occurred for none of these 30 patients. This method seems to be a desirable method in treatment of fissure with minimum side effects and great success.

\section{Conflicts of interest}

The authors declare no conflicts of interest.

\section{REFERE N C E S}

1. Scholz T, Hetzer FH, Dindo D, Demartines N, Clavien PA, Hahnloser D. Long-term follow-up after combined fissurectomy and Botox injection for chronic anal fissures. Int J Colorectal Dis. 2007;22:1077-81.

2. Collins EE, Lund JN. A review of chronic anal fissure management. Tech Coloproctol. 2007;11:209-23.

3. Tranqui P, Trottier DC, Victor C, Freeman JB. Nonsurgical treatment of chronic anal fissure: nitroglycerin and dilatation versus nifedipine and botulinum toxin. Can J Surg. 2006;49:41-5.

4. Nelson RL, Thomas K, Morgan J, Jones A. Non surgical therapy for anal fissure. Cochrane Database Syst Rev. 2012:CD003431. 
5. Haq Z, Rahman M, Chowdhury RA, Baten MA, Khatun M. Chemical sphincterotomy - first line of treatment for chronic anal fissure. Mymensingh Med J. 2005;14:88-90.

6. Shao WJ, Li GC, Zhang ZK. Systematic review and meta-analysis of randomized controlled trials comparing botulinum toxin injection with lateral internal sphincterotomy for chronic anal fissure. Int J Colorectal Dis. 2009;24:995-1000.

7. Chambers W, Sajal R, Dixon A. V-Y advancement flap as first-line treatment for all chronic anal fissures. Int $J$ Colorectal Dis. 2010;25:645-8.

8. de la Portilla F, Calero-Lillo A, Jiménez-Rodríguez RM, Reyes ML, Segovia-González M, Maestre MV, et al. Validation of a new scoring system: rapid assessment faecal incontinence score. World J Gastrointest Surg. 2015; 7:203-7.
9. Giordano P, Gravante G, Grondona P, Ruggiero B, Porrett T, Lunniss PJ. Simple cutaneous advancement flap anoplasty for resistant chronic anal fissure. World J Surg. 2009;33:1058-63.

10. Nelson R. Non surgical therapy for anal fissure. Cochrane Database Syst Rev. 2006:CD003431.

11. Farkas N, Solanki K, Frampton AE, Black J, Gupta A, West NJ. Are we following an algorithm for managing chronic anal fissure? A completed audit cycle. Ann Med Surg (Lond). 2015;5:38-44.

12. Chambers W, Sajal R, Dixon A. V-Y advancement flap as first-line treatment for all chronic anal fissure. Int J Colorectal Dis. 2010;25:645-8.

13. Patti R, Famà F, Tornambè A, Restivo M, Di Vita G. Early results of fissurectomy and advancement flap for resistant chronic anal fissure without hypertonia of the internal anal sphincter. Am Surg. 2010;76:206-10. 